\title{
GEOGRAFIA, GEOGRAFÍA FÍSICA E MEIO AMBIENTE: UMA REFLEXÃO À PARTIR DA PROBLEMÁTICA SOCIOAMBIENTAL URBANA ${ }^{1}$
}

\author{
Francisco Mendonça \\ Professor Titular da UFPR \\ chico@ufpr.br
}

\begin{abstract}
Resumo
A questão ambiental tomou, na atualidade, importante dimensão no âmbito institucional geral e também em todas as preocupações sociais, pois os problemas a ela relacionados intensificaram-se fortemente na modernidade. A abordagem científica moderna tem se mostrado insuficiente para o trato amplo da problemática ambiental que se manifesta na cidade. Ageografia, no seu particular, apresenta possibilidades interessantes para o tratamento desta problemática, mesmo se a perspectiva das ciências naturais - geografia física - e das ciências sociais - geografia humana - encontre ai vários problemas. Considerando a complexidade dos problemas socioambientais urbanos, e a emergência da abordagem dos riscos e vulnerabilidades socioambientais urbanas, acredita-se que o enfoque integrado dos dois subamos da geografia encontrem nesta perspectiva uma maior interação. Dentro deste contexto o SSAU - Sistema Socio-Ambiental Urbano, uma proposta metodológica para o estudo integrado da cidade, é apresentado.
\end{abstract}

Palavras-chave: Urbanização, cidade, geografia, problemas socioambientais, SSAU.

\begin{abstract}
The environmental problems have, in actuality, an important dimension into the institutional and in the all social dimensions, because they have been intensified sharply in modernity. The modern scientific approach has shown itself insufficient for the large tract of environmental problems manifested in the city. Geography, in its particular, presents interesting possibilities for the treatment of environmental question, even if the prospect of the natural sciences - physical geography - and the social sciences - human geography - have different approach. Considering the complexity of urban environmental problems, and the emergence of an approach to risk and vulnerability in the city, it is certain that the integrated approach of both geography would do a good interaction. Within this context the SSAUR (Urban Socioenvironmental System), a methodology for the integrated study of the city, is shown at the end of paper.
\end{abstract}

Key-words: Urbaniation, city, geografhy, socioenvironmental problems, SSAU.

\section{$\circ \bigcirc \circ$}

\section{INTRODUÇÃO}

“(...). Quem quiser poderá observar a estupidez com que pensam, julgam e atuam hoje na política, na arte, na religião e nos problemas gerais da vida e do mundo os"homens de ciência” e é claro que, além deles, médicos, engenheiros, economistas, professores, etc. (...).

O resultado mais imediato dessa especialização não compensada é que hoje, quando há maior número de "homens de ciência" que nunca, há muito menos "homens cultos" do que, por exemplo, por volta de 1750 . (...)". (ORTEGA; GASSET, 2002; 150)

Quaisquer que sejam as concepções que adotemos de espaço geográfico, em todas elas fica evidente a dimensão material da superfície da Terra como objeto de investigação e reflexão geográfica. Não sendo uniforme nem homogênea, em função de sua dinamicidade em distintas temporalidades, a superfície do planeta sempre suscitou questionamentos aos homens e suas sociedades, fundamento principal da constituição do pensamento e do conhecimento geográfico. 
Formado por um rico e complexo mosaico de paisagens o espaço geográfico tem, como gênese de sua diferenciação, tanto as construções próprias da Natureza quanto a produção da Sociedade humana. Desta condição deriva a concepção de que a geografia é uma ciência voltada ao estudo da produção do espaço a partir da interação Sociedade-Natureza. Importa, à geografia física, o conhecimento aprofundado da composição e dinâmica processual da primeira, bem como as derivações oriundas de sua apropriação e transformação pela segunda.

Natureza e Sociedade são, de maneira geral, tomadas como termos gerais na produção do conhecimento geográfico. Uma preocupação, mesmo que introdutória, da dimensão teórico-epistemológica destes termos revelará uma expressiva variedade de concepções dos mesmos, embora se observe, no discurso geográfico da hipermodernidade, um considerável enfraquecimento deste tipo de enfoque.

Tomadas como partes integrantes do espaço geográfico na nascente geografia oitocentista, Natureza e Sociedade passaram a ser, rapidamente, enfocadas de forma dissociada em conseqüência do fortalecimento da perspectiva positivista na modernidade durante o século XX. Todavia, as intensas e complexas transformações impressas na paisagem decorrentes da intensificação das relações de produção, nas ultimas décadas do século passado e no inicio do XXI, impuseram aos geógrafos a necessidade de tomá-lo sob perspectivas mais integradoras. É nesta perspectiva que a questão ambiental constitui tanto uma possibilidade de avanço da analise geográfica no presente, como também apresenta limitações e desafios a esta ciência. Para contribuir com o debate acerca deste enfoque, ou seja, da dimensão ambiental no contexto da ciência geográfica, o presente texto traz uma reflexão introdutória de cunho histórico-filosófico na sua primeira parte.

Na segunda parte o enfoque liga-se à uma das mais evidentes características espaciais da modernidade, na sua fase globalizada, manifestada no acelerado processo de expansão e densificação das áreas urbanas, em alguns casos formando cidades gigantescas ou megacidades, fortemente marcadas por problemas socioambientais. Tais problemas, bem como as repercussões de sua dinâmica sobre o entorno próximo e distante, requer uma abordagem diferenciada do espaço pelos geógrafos, tanto físicos quanto humanos. Nesta perspectiva a segunda parte do texto expõe uma proposta teórico-metodológica para a analise socioambiental urbana, e conclui apresentando uma série de aspectos que, mais que apontar soluções para os problemas socioambientais sob o enfoque geográfico, delineia um cenário de desafios para esta ciência.

Para uma melhor compreensão do texto lançamos mão do uso de um esquema (figura 1), cuja leitura pode ser feita de maneira dinâmica, tendo por base o movimento entre suas partes constitutivas. $\mathrm{O}$ triangulo, termos, círculos e setas são empregados na figura para imprimirem uma perspectiva de movimento do pensamento, pois busca articular temporalidades não datadas, concepções mutantes e processos sempre em criação e alteração, de forma a evidenciar uma idéia de fazer e re-fazer constante, sempre em construção e transformação.

\section{A GEOGRAFIA (FÍSICA) APLICADA E O PERIGO DO ESVAZIAMENTO TEÓRICO- METODOLÓGICO}

"La thématique (environnement) est univoque: étudier sur les franges incertaines des sciences de la société et des sciences de la nature les espaces géographiques, paysages et territoires qui nous entourent et, dans une certaine mesure, nous conditionnent. En les appréhendant globalement comme des objets, ou des sujets mixtes, à la fois naturels et sociaux. Presque toujours anthropisés, presque toujours artificialisés. Le principe d'hybridation est le fil directeur de notre recherche.” (BERTRAND et BERTRAND, 2002 ; p. 1.) 
No final do século XX e inicio do XXI a compressão do espaço devido à aceleração do tempo, característica singular do processo de globalização (Santos, 2005; Souza Santos, 2005), se fez acompanhar de uma intensificação, sem precedentes na historia das sociedades, da pressão humana sobre a natureza e sobre os recursos naturais do planeta. Praticamente todas as localidades da superfície da Terra, em todos os instantes, encontram-se impregnadas da ação humana, sendo que o mosaico de paisagens que forma o espaço geográfico atesta, de maneira direta e indireta, uma condição jamais observada na historia da natureza e na historia da sociedade humana. É certamente este o momento em que se pode verificar profundas alterações na formação e composição exclusivamente natural das paisagens, daí a predominância de paisagens humanizadas na Terra, fato que explica o porquê de as mudanças globais terem ganhando tamanho destaque no âmbito das preocupações e debates gerais do presente.

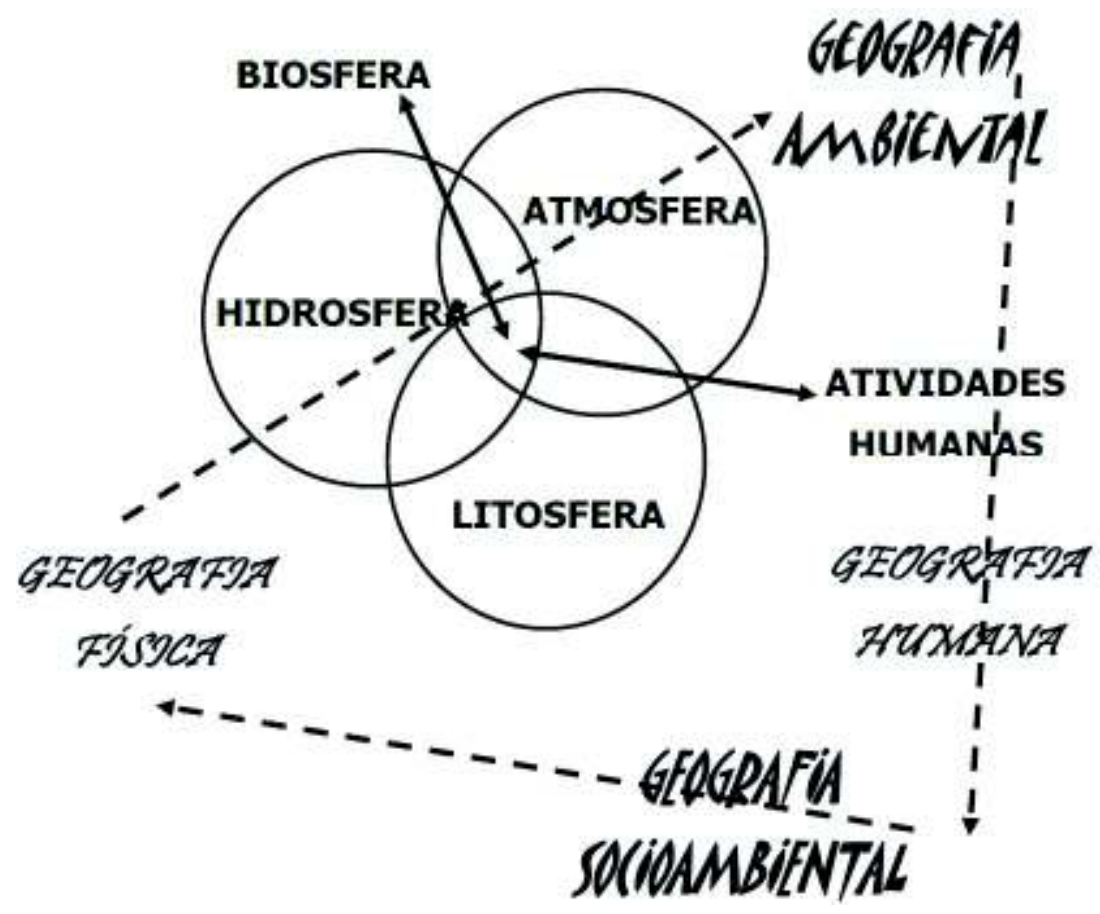

Figura 1 - Abordagem ambiental na Geografia Moderna

Malgrado os avanços tecnológicos e a crescente e volumosa riqueza social auferida da apropriação e transformação da natureza do planeta, os resultados da ação humana neste processo derivam, sobretudo, cenários de degradação e comprometimento das bases da vida humana. Vários movimentos surgem então no sentido tanto de deter o processo de degradação e destruição da natureza - portanto, autodegradação e autodestruição humana - quanto de procurar soluções para equacionar o complicado espectro de conflitos socioambientais que marcam o presente momento.

Se os mais graves problemas deste contexto se fizeram sentir nas fases mais recentes da modernidade, ou hipermodernidade - fase atual, derivando especulações exageradamente alarmistas quanto ao futuro 
próximo da humanidade face aos acidentes e catástrofes naturais — natural hazards, a origem dos mesmos remonta à fase de complexização da relação sociedade-natureza.

É certamente neste contexto de busca de soluções para a problemática e conflituosa relação entre a sociedade e a natureza no Ocidente que se observa uma considerável reorientação na abordagem dos estudos ligados à geografia física no Brasil. Até meados do século XX o enfoque físico-geográfico esteve mais voltado ao desvendamento da natureza, evidenciando suas diferentes manifestações espaço-temporais, donde uma fase caracteristicamente exploratória e descritiva (MENDONÇA, 1993). Nesta perspectiva a paisagem geográfica era tomada sob uma concepção fragmentada e com elementos desconexos, importando ai, sobretudo, o conhecimento aprofundado de seus constituintes — litosfera / relevo / geomorfologia, hidrosfera / hidrografia e atmosfera / climatologia (figura 1 - do canto inferior esquerdo ao centro médio superior esquerdo); a biosfera / biogeografia ${ }^{2}$ completa o conjunto dos elementos constitutivos dos estudos em geografia física.

Nesta fase foram registrados os principais avanços teórico-metodológicos da geografia física, pois resultam, numa perspectiva dialética, da interação entre teoria e empiria na produção do conhecimento científico de então. O desvendamento dos diferentes aspectos da paisagem, e sua conseqüente explicação, levaram ao estabelecimento de teorias e à formulação de leis gerais que embasaram a nascente geografia cientifica moderna. A parte final desta fase é marcada por um conjunto de proposições para a delimitação de paisagens (métodos) que cobrem a esfera terrestre, da escala global às escalas de detalhe.

Embora um número expressivo de geógrafos, influenciados pela perspectiva ecosistêmica, tomasse o geosistema como a escala preferencial de abordagem da organização e dinâmica das paisagens (Monteiro, 2000; Bertrand et Bertrand, 2002), os demais não ficaram restritos a esta escala de estudos dos fenômenos físico-geográficos. À abordagem da geografia física não escapava a atenção aos estudos da superfície na sua dimensão global, zonal, regional (o geosistema), local e topológica. O salto que se observa a partir de meados do século é, marcadamente decorrente do contexto histórico, a postura relacional e conectiva com relação ao enfoque dos elementos componentes do espaço geográfico.

O conhecimento fragmentado, mesmo que aprofundado, dos componentes da natureza e da sociedade que caracterizara o momento anterior não mais lograra êxito, ou eficácia, diante da imperante necessidade de avançar na compreensão dos problemas ambientais; a possibilidade de intervenção, buscando reverter a degradação ambiental dos diferentes lugares da Terra, urgia. De uma perspectiva predominantemente nomotética a geográfica física, por uma série de características, parece avançar para uma mais idiográfica, posto que a possibilidade de intervenção dos geógrafos parecia se concretizar em dimensões do espaço de maior proximidade, ou na escala da região e do lugar.

A busca de interações com outros campos do conhecimento, tendo em vista que a perspectiva ambiental evidencia uma postura eminentemente relacional, torna-se imperativa diante deste contexto. Assim é que o desenvolvimento da geografia aplicada coloca-se como uma cada vez mais importante possibilidade de atuação dos geógrafos físicos que, primeiramente e por um bom período de tempo, mantêm-se no âmbito da própria geografia física ao elaborar estudos caracterizados pelo ambientalismo naturalista (figura 1 - da parte central ao canto superior esquerdo), conforme Mendonça (1993).

Em muitos trabalhos se observa a busca de articulações e do jogo de influencias que se desenvolvem entre o relevo e o clima, entre este e a vegetação, desta com os solos, com a hidrografia, desta com aqueles e de vários deles entre si. A ação humana ganha, de maneira lenta mas cada vez mais forte, importância na analise físico-geográfica, constituindo-se num fator dinamizador da paisagem e não um de seus elementos componentes na perspectiva da geografia física. 
Trata-se assim de um contexto histórico no qual a distinção entre a abordagem de uma geografia física clássica e de uma geografia física ambiental torna-se cada vez mais tênue. Parece ficar evidente a constituição de dois enfoques relativamente diferenciados; aquele de uma "geografia física pura", com característica predominante de ciência básica, voltado ao conhecimento da constituição e dinâmica processual dos elementos da paisagem, na qual se destaca uma perspectiva teórico-metodológica na elaboração dos estudos, e um outro mais relacional e de caráter mais aplicado, no qual a perspectiva teórica ou teorizante se secundariza.

Esta realidade expressa uma condição singular, aquela de um certo distanciamento entre a dimensão teórica e a dimensão aplicada do conhecimento geográfico, aspecto que desafia os geógrafos à uma reflexão profunda entre a teoria e a empiria na produção de seu conhecimento, ao que Demo (1997, pg. 28) muito apropriadamente chamara a atenção.

No que concerne às preocupações com a evolução da geografia a partir de meados do século XX, verifica-se que as geotecnologias são amplamente empregadas, derivando uma enormidade de estudos ligados a um variado leque de aplicações tanto científicas quanto no campo do planejamento e da gestão territorial. Desde as fotografias aéreas, passando pelas imagens de satélites e pelos diversificados e cada vez mais complicados processos computacionais / informacionais (sensoriamento remoto e geoprocessamento) até a modelização da paisagem, o que se observa, de maneira geral, além de um cada vez mais sofisticado produto ilustrativo/cartográfico, é a intensificação do risco de empobrecimento da analise destes mesmos produtos.

Fortemente marcada pelos apelos do "desenvolvimento sustentável” e por um reforço do fundamento neopositivista, esta nova fase conduz a um enfraquecimento da necessária base teórico-geográfica para a interpretação e analise da paisagem, cuja representação gráfica, qualquer que seja, constitui apenas mais um elemento do fazer geográfico. Os geógrafos físicos deparam-se então e doravante com um importante desafio, qual seja, aquele de não deixar sucumbir a capacidade cientifica em face dos rápidos e deslumbrantes resultados derivados do emprego da tecnologia, e da cada vez maior demanda de sua contribuição na gestão dos espaços e territórios; uma perspectiva não anula ou exclui a outra... Elas são eminentemente complementares.

Envolvida pela emergência e pela planetarização das preocupações com as mudanças globais, que são alçadas aos grandes fóruns mundiais de decisão econômica e política no final do século XX, a questão e problemática ambiental colocam-se numa nova dimensão, aquela da dimensão socioambiental (Mendonça, 2001; Veiga, 2007). A complexidade que reveste este momento da história da humanidade demanda um considerável esforço dos geógrafos, particularmente aos geógrafos físicos, qual seja, o de envolver a sociedade humana de maneira mais direta no tratamento dos impactos e riscos que envolvem a degradação ambiental generalizada que se expressa nas paisagens da Terra (figura 1 - canto inferior direito). Neste sentido, e coadunando-se com as inquietações da sociedade do presente,

Environmental geography covers the issues of environmental degradation, quality of environmental degradation, and the condition of life. It is actually made up of geography - physical geography, human geography, regional geography, economic geography - that deal with different parts of the environment, human population, land use, and their interrelations. (...). (MARSH and GROSSA JR, 2001, p. 14).

As situações diferenciadas de vulnerabilidades da sociedade ante aos processos da natureza explicitam a condição humana-social dos problemas ambientais - donde socioambientais, fato que desafia o saber e o conhecimento geográfico a uma maior conjunção e complementaridade (Mathews and Herbert, 2004), 
afinal “... na ciência, o objeto de investigação não é a Natureza em sim mesma, mas a Natureza submetida à interrogação dos homens" (Heinsenberg apud Santos, 1992 pg. 11).

Transformações e mudanças muito intensas das paisagens, derivadas das atividades humanas geradoras de impactos, riscos e condições de vulnerabilidades socioambientais demandam, então, novas posturas teórico-metodológicas dos geógrafos. Muitas então são as possibilidades de avanço do pensar e fazer geográfico dos dias atuais, pois que as mudanças globais e a globalização se manifestam em todas as escalas do geográfico. Para ilustrar os argumentos supra-apresentados o enfoque na segunda parte deste texto volta-se ao estudo da cidade numa nova perspectiva, pois que os espaços urbanos configuram-se nas áreas de mais intensa alteração da paisagem natural pela ação humana, sendo que neles a perspectiva da abordagem socioambiental encontra um eloqüente exemplo.

\section{CIDADE, ESPAÇO URBANO E MEIO AMBIENTE}

"Enquanto riscos naturais são ampliados pela pobreza urbana, riscos novos e totalmente artificiais são criados pela interação entre pobreza e industrias poluentes, trânsito anárquico e infra-estrutura em colapso. (...)”. (MIKE DAVIS, 2006, pg. 134).

Os problemas socioambientais urbanos são eivados de alta complexidade, particularmente nas grandes cidades. A solução para os mesmos constitui um enorme desafio aos cientistas, técnicos, políticos, gestores e citadinos em geral, posto que as repercussões negativas dos mesmos sobre uma parcela cada vez maior de pessoas configura uma ameaça permanente.

Tomada ao longo da história a partir de posições fragmentadas, desconexas, distintas, e muitas vezes contraditórias, a cidade e o espaço urbano configuram hoje um rico cenário de investigação científicotécnica, ao mesmo tempo que constituem uma excelente oportunidade para o avanço do conhecimento científico.

Do ponto de vista geográfico um dos principais desafios apresentados pelas áreas urbanas diz respeito à sua dimensão multiescalar. As cidades configuram manifestações locais de processos que se produzem na dimensão de espaços ora distantes ora próximos, ora fixos e ora fluxos, e que se evidenciam de forma mais expressiva pontualmente, tendo interações e repercussão em diversos processos na dimensão areal.

$\mathrm{Na}$ perspectiva da geografia física a heterogeneidade do espaço geográfico tem, na constituição e dinâmica da Natureza, a matriz de sua gênese, característica que reflete a vinculação da geografia física aos princípios das ciências naturais. A divisão da superfície terrestre em espaços diferenciados conforme distintos processos naturais, compreendidos como paisagens, geosistemas, biomas e bacias hidrográficas, por exemplo, obedece a uma delimitação de base estritamente naturalista. A cidade e os espaços urbanos, ao contrário, resultam de construções humanas derivadas de processos sociais distintos sendo, no âmbito da ciência geográfica, objeto de estudo da geografia humana, que tem vínculos estreitos com as ciências humanas e sociais. Assim é que os espaços urbanos expressam-se na forma de pequenas manchas, ou pontos, dentro de grandes áreas delimitadas por processos naturais; esta interação aparece, cada vez mais, como instigadora à compreensão das áreas urbanizadas, sua complexidade intrínseca e interna, e seus entornos.

Todavia, a cidade se interpõe como fato e como problema de estudo e de gestão entre estas duas dimensões escalares espaço-temporais, quais sejam, a da dinâmica da natureza (dimensão areal-pontual) e a dinâmica da sociedade (dimensão pontual-areal). Neste sentido é que os problemas socioambientais urbanos demandam uma nova postura cientifica, técnica e política à sociedade do presente, pois que a solução dos mesmos passa por uma reformulação do estatuto da modernidade - ou pelo menos do Estado- 
Nacional burguês (SERRES, 1993) - de forma profunda. Novas propostas teóricas e metodológicas têm sido lançadas neste afã, tal como o Sistema Ambiental Urbano que se verá a seguir.

\section{A abordagem socioambiental urbana - Uma perspectiva}

A formação de "superurbanizações" e "megacidades"- que podem merecer a alcunha de"'leviatã", como a região que engloba São Paulo, Rio de Janeiro e Campinas - abre uma longa lista de temas como por exemplo o crescimento de favelas provocado por guerras, expulsões catastróficas, recessão econômica (como no caso da América Latina), alto crescimento econômico e urbano (como nos casos da Índia e China), segregação, racismo; tragédias decorrentes de desmoronamentos, enchentes, incêndios, terremotos (que vitimam sobretudo os pobres); áreas contaminadas, explosões tóxicas; os males do transporte rodoviarista como a poluição do ar e os acidentes de transito, entre outros. (Ermínia Maricato, in MAKE DAVIS, 2006, pg. 209.).

Por um considerável período os problemas relacionados aos espaços citadinos e ao ambiente urbano foram tratados na perspectiva de impactos ambientais urbanos. Nesta abordagem, dentro da qual inúmeras contribuições foram lançadas visando a solução dos problemas que afligem os homens nas cidades, privilegiou-se, na maioria das vezes, um enfoque da suscetibilidade urbana aos desastres naturais. Neste contexto ganharam destaques estudos relativos ao verde urbano, à degradação hídrica, do ar e dos solos, às inundações e aos movimentos de massa e deslizamentos de terras, etc.

A sociedade urbana, entretanto, ao vivenciar problemas de extrema gravidade para a maioria da população, manifestados em diversos processos de exclusão e injustiça social, passou a demandar uma abordagem mais complexa dos problemas ambientais ali presentes. Assim é que, ao se encontrarem expostas a fenômenos naturais, tecnológicos ou sociais impactantes e de ordem eventual e/ou catastróficos, parcelas importantes da população passaram a evidenciar condições de risco e de vulnerabilidade socioambiental face aos perigos atinente ao sitio e à dinâmica dos ambientes urbanos.

A noção de risco e de vulnerabilidade socioambiental liga-se tanto às ciências da natureza quanto às ciências da sociedade, tanto às ciências básicas quanto às ciências aplicadas, tanto à academia quanto à sociedade em sua dimensão ampla e complexa. Riscos e vulnerabilidades socioambientais urbanos remetem à uma abordagem dual e de interface sobre a cidade, aspecto que evidencia o necessário exercício do diálogo e troca de saberes que explicitam, portanto, a construção de um conhecimento mais complexo que aquele gestado pela modernidade.

Nesta perspectiva as condições de vida da população assumiram, paulatinamente, papel decisivo no enfoque do estudo e gestão dos espaços urbanos. $\mathrm{O}$ atrelamento entre as condições-modo de vida urbana encontram-se na gênese dos problemas ambientais urbanos, fato que os torna socioambientais, e revelam, ao mesmo tempo, diferenciações claras entre a cidade formal, a cidade informal e a cidade do cotidiano. Conforme Grazia e Queiroz (2001: 91)

Embora a cidade informal careça das condições necessárias à vida no cotidiano urbano, ela é acessível aos assentamentos de baixa renda que a ocupam e que desempenham um papel na estrutura econômica e social das cidades. Um agravante à qualidade de vida na cidade informal é a sua localização, frequentemente em áreas sujeitas a perigos naturais, como enchentes e deslizamentos, e a perigos tecnológicos, como contaminações e explosões, constituindo-se em risco para sua população.

Para estes autores a condição de pobreza de uma determinada população está estreitamente vinculada à condição de formação de riscos e de vulnerabilidade socioambiental, pois (2001:44)

(...) a par do comportamento especulativo do capital imobiliário, os pobres são muitas vezes impelidos a criar uma cidade ilegal nos interstícios da cidade legal, muitas vezes aproveitando áreas públicas ociosas e/

Revista da ANPEGE. v. 5, 2009 
ou de preservação ambiental, incapazes que são de competir no mercado formal da terra urbana. Enquanto o consumo de produtos modernos é estimulado pela mídia e facilitado pelo crédito, o mesmo não ocorre em relação à habitação. Esses moradores constroem por seus próprios meios suas moradas, sem assistência técnica ou financiamento, já que a irregularidade fundiária implica, em geral, em fortes obstáculos ao acesso ao crédito e aos programas habitacionais oficiais. As favelas, mocambos, alagados ou assentamentos clandestinos ou irregulares surgem, proliferam-se, adensam-se, constituindo a única alternativa habitacional para uma grande parte da população que enfrenta, nesse caso, a insegurança quanto à permanência e à precariedade das condições locais".

A noção de vulnerabilidade envolve também aspectos relativos à gestão urbana pois, como o acenaram Dubois-Maury et Chaline (2002: 10), "a vulnerabilidade da cidade concerne evidentemente aquela parcela dos homens e dos bens que ela concentra, mas ela implica, muitas vezes também, aquela de seus poderes, de sua imagem e de sua dimensão". Estes autores concebem ainda que (Op Cit: 21)

A vulnerabilidade urbana aos riscos, sejam eles endógenos ou exógenos, é uma noção complexa porque pode ter conteúdos humanos, econômicos, patrimoniais, tecnológicos e organizacionais que se diversificam no espaço e no tempo. O fato fundamental reside na acumulação de homens e de atividades que é própria da cidade, mas que induz à fragilidade. (...).

Riscos e vulnerabilidades socioambientais formam um par indissociável no tratamento dos problemas urbanos. A imbricação entre uns e outros à constatação de que, conforme Acselrad (2004), não é possível enfrentar a crise ambiental sem promover a justiça social, dado que observa-se nitidamente na cidade contemporânea a existência de condições de desigualdade social e de poder sobre recursos ambientais, em cujo contexto os instrumentos de poder sobre o controle ambiental tendem a aumentar a desigualdade ambiental.

Este tipo de enfoque encontra forte respaldo na concepção de sociedade de risco de Beck (1998), para quem há uma estreita ligação entre a formação dos riscos ambientais e as condições de pobreza social. Para ele ha uma maior vulnerabilidade de certas comunidades frente aos riscos, por mais genéricos e absolutos que eles possam ser; esta concepção revela o fato de que tanto o risco, como a vulnerabilidade e a catástrofe, se materializam em território determinados e que têm, portanto, um componente espacial que se baseia na coincidência de uma determinada ameaça para a população e suas atividades.

A noção de vulnerabilidade socioambiental urbana evidencia ainda que, observando-se as várias concepções, as manifestações bruscas e repentinas da natureza (natural hazards) e o meio-ambiente constituem os dois principais responsáveis pelo maior numero de problemas socioambientais urbanos. Também é verdade que sozinhos eles não respondem muito, tornando-se imperativo o envolvimento da análise socioeconômica, cultural e política da sociedade face aos riscos urbanos.

Analisados sob o enfoque da abordagem geográfica os riscos e as vulnerabilidades socioambientais urbanos permitem uma perfeita articulação entre os conhecimentos do sitio urbano - e da qualidade de vida a ele associada, e aqueles da dimensão social da cidade - as atividades humanas e a concretude do espaço construído. Esta nova perspectiva de enfoque da cidade possibilita o rompimento da clássica dualidade e dicotomia do conhecimento geográfico, pois a problemática socioambiental urbana explicita a dupla dimensão da cidade, qual seja a natureza (alterada) e a sociedade que a formam.

\section{O SSAU - Sistema Socioambiental Urbano.}

Mendonça (2004), considerando as concepções acima em sua análise, e buscando apontar novas perspectivas metodológicas para os estudos relativos à problemática socioambiental urbana, revisita os 
conceitos de ambiente urbano proposto pelo PNDU/UNOPS (1997) com seus três subsistemas (natural, social e construído), e de SCU - sistema clima urbano de Monteiro (1976). Considerando também a cidade como um Sistema Dinâmico, como a concebem Dubois-Maury et Chaline (2002), propõe o SAU - Sistema Ambiental Urbano - como perspectiva compreensiva e metodológica para o estudo dos problemas socioambientais urbanos, esquematizado na figura 2. Esta proposta coloca em evidencia o fato de que, para se elaborar estudos e intervenções na perspectiva do S.A.U., deve-se trabalhar com problemas emanados da interação sociedade-natureza.

O S.A.U. constitui um sistema complexo e aberto. Ele se subdivide, primeiramente, em três subsistemas (input e atributos - figura 2), podendo ser subdivido numa considerável quantidade de subsistemas ou instancias daqueles. Assim, o pesquisador pode escolher trabalhar, por exemplo, com o Subsistema Hídrico (Subsistema Águas Urbanas) como parte do Sistema Natural, fortemente influenciado e alterado pelo Subsistema Industria que é, por usa vez, dinamizado pelos Subsistemas Cultural, Econômico e Político da cidade. Os problemas relacionados à qualidade da água, ao abastecimento, esgotamento sanitário, poluição, etc. deste subsistema demandam ações sociais e políticas públicas que, embasadas em estudos e propostas de planejamento e gestão poderão encaminhar o equacionamento do problema.

\section{S. A. U. - SISTEMA AMBBIENTAL URB ANO}

(Simplificado)

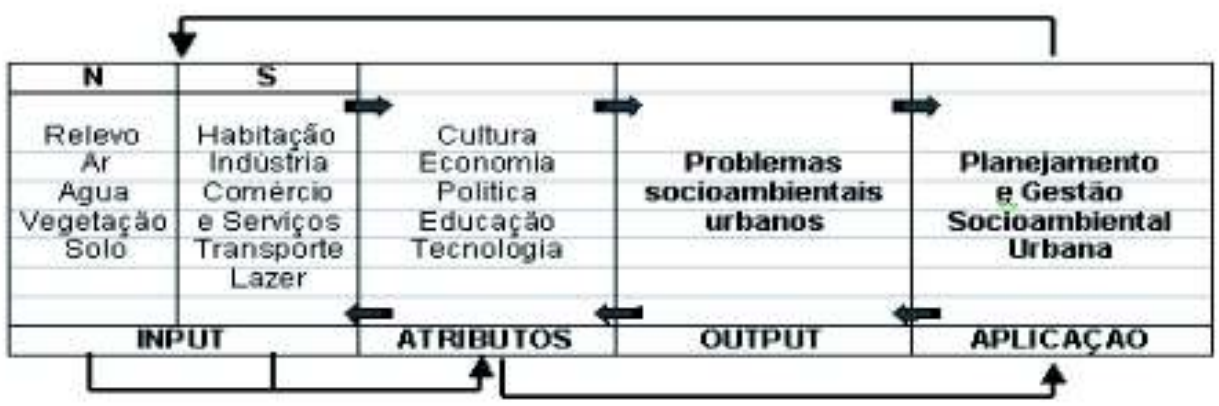

Figura 2 - SAU

Fonte: Mendonça, 2004.

Parece óbvio, mas não é demais ressaltar que a água na cidade, ainda que elemento da natureza, é ali fortemente alterada, mas precisa apresentar condições mínimas de potabilidade para o uso residencial e industrial; ela é sempre um exemplo didático, isto para não falar nos outros elementos da natureza na cidade, que evidenciam a necessidade de compreender que a tecnologia ainda não subverteu a condição humana do homem.

De maneira esquemática o S.A.U. é assim composto:

1. Input do S.A.U. - Fluxos de matéria e energia, tanto de ordem natural quanto derivados dos processos sociais. Ele é então composto pelo Subsistema Natureza e pelo Subsistema Sociedade, podendo ser ainda subdividido em vários subsistemas, tais como os Subsistemas N (relevo, ar, água, vegetação e solos) e Subsistemas S (habitação, industria, comercio, serviços, transporte, lazer).

Revista da ANPEGE. v. 5, 2009 
2. Atributos do S.A.U. - São as instancias sociais (Subsistema Sociedade) que imprimem a dinâmica / movimento do sistema ambiental na cidade. Neste âmbito prevalecem as características pertencentes à superestrutura da sociedade (economia, política) e a cultura da população que a constitui, além da educação e da tecnologia. As manifestações abruptas, episódicas e impactantes da natureza também aparecem como importantes dinamizadores do S.A.U.

3. Output do S.A.U. - Aqui aparecem os vários problemas resultantes da interação entre os vários subsistemas e subsubsistemas do S.A.U., e que demandam a atenção da população, dos governantes, da sociedade organizada e das instituições.

4. Aplicações - Nesta particularidade do S.A.U. devem ser estudadas e elaboradas as propostas para o equacionamento dos problemas socioambientais urbanos. A solução dos mesmos terá implicação direta na qualidade de vida das populações envolvidas, o que promoverá uma alteração do input, dos atributos e do output do S.A.U por intermédio de mecanismos de feedback.

\section{SINTETIZANDO AS REFLEXÕES}

A analise desenvolvida ao longo do texto prendeu-se a dois enfoques; um primeiro mais voltado à teoria e epistemologia da geografia física, tendo como preocupação sua evolução e traansformações, e o segundo buscando evidenciar um olhar sobre a cidade que aposta na interação entre a dimensão da natureza e da sociedade na elaboração de estudos sobre os problemas socioambientais urbanos.

Geografia física e geografia ambiental não são sinônimos, há que mais uma vez se assinalar. Se a realidade do presente, face à emergência das questões ambientais, tem apresentado novos e importantes desafios aos geógrafos, particularmente aos geógrafos físicos neste contexto, o conhecimento aprofundado da geografia física do planeta não pode ser deixado de lado ou enfraquecido. A analise ambiental do presente necessita de sólido embasamento físico-geográfico para ser melhor elaborada, tanto quanto das geotecnologias, ressalvando-se a necessária e permanente atenção para com as ameaças do neopositivismo no emprego das novas ferramentas de analise do espaço geográfico.

A perspectiva socioambiental coloca-se como um instigante desafio aos geógrafos, tanto físicos quanto humanos, pois constitui-se numa oportunidade impar de maior integração entre as especificidades do geográfico, vide a epígrafe de Ortega Y Gasset na abertura deste texto. O estudo da cidade e dos espaços urbanos, a partir da perspectiva socioambiental, encontra na proposta do S.A.U. - Sistema Socioambiental Urbano - uma oportunidade de retomada dos estudos na perspectiva de ligar o físico-natural e o humano-social na cidade e na geografia.

Mesmo se a perspectiva de analise sobre a cidade tenha se prendido à abordagem dos problemas socioambientais urbanos, há que se acenar para o fato de que os espaços urbanos não são constituídos somente de problemas. Muitos dos sonhos e utopias humanas e sociais se realizam nestes contextos mas, infelizmente, a maior parte das populações humanas que habitam nas cidades dos "países do Sul" vivem em condições sociais e ambientais muito ruins. Intervir sobre estas realidades buscando melhorias nas condições e qualidade de vida das populações torna-se um imperativo, para o que a geografia - geografia física - tem muita a contribuir. Se as limitações teórico-metodológicas ecoam como um clamor para a busca de novas bases para compreensão da complexidade socioambiental urbana, a intervenção técnica da gestão conclama os geógrafos a uma urgente participação. 


\section{NOTAS}

(1) Este texto foi originalmente produzido como base da conferencia de abertura do V Simpósio Latino-americano de Geografia Física, realizado em Santa Maria/RS, em maio de 2008. Ele foi encaminhado para publicação a convite dos organizadores do evento e, na presente oportunidade, encontra-se parcialmente alterado quando comparado àquela versão.

(2) A biosfera / biogeografia constitui um capítulo em separado dentro da geografia física, desde o Tratado de Geografia Física de Emannuel De Martonne (1948 e 1950) lançado em 1909, até a perspectiva geosistêmica de Georges Bertrand (exploração biológica; 1972) e os Conteúdos Básicos de Geografia física previstos nos documentos relativos ao ensino superior no Brasil. Todavia, sua abordagem sempre esteve muito diretamente afeta aos estudos da Geografia Física.

\section{REFERENCIAS BIBLIOGRÁFICAS}

ACSELRAD, Henry. (Coord.). Justiça ambiental e cidadania. Rio de Janeiro: Relume Dumará: Fundação FORD, 2004.

BECK, Ulrich. La sociedad del riesgo. Hacia una nueva modernidad. Madrid: Paidos, 1998.

BERTRAND, Georges e BERTRAND, Claude. Une géographie traversière - L'environnement à travers territoires et temporalités. Paris : Editions Arguments, 2002.

DAVIS, Mike. Planeta Favela. São Paulo: Boitempo, 2006.

DE MARTONNE, Emmanuel. Traité de geographie physique. Paris: Armand Colin, Tomos I - Climat e Hidrographie, e II - Le relief du sol, 1948.

. Traité de geographie physique. Paris: Armand Colin, Tomo III - Biogéographie, 1950.

DEMO, Pedro. Pesquisa e construção de conhecimento - Metodologia cientifica no caminho de Habermas. Rio de Janeiro: Tempo Brasileiro, 1997.

DUBOIS-MAURY, J. et CHALINE, C. Les risques urbains. Paris : Armand Colin, 2002.

GRAZIA, G. QUEIROZ, L. L. et al. O desafio da sustentabilidade urbana. Rio de Janeiro: FASE/IBASE, 2001. (Série Cadernos Temáticos, n.5).

MARICATO, Erminia. Posfácio. In: DAVIS, Mike. Planeta Favela. São Paulo: Boitempo, 2006.

MARSH, William M. and GROSSA JR, John M. Environmental geographie - Science, land use, and Earth Systems. Londres: John wiley and sons, 2001.

MATHEWS, J. A. and HERBERT, D. Unifying geography - Commom heritage, shared future. Oxfordshire : Routledge, 2004.

MENDONÇA, Francisco. Geografia e meio ambiente. São Paulo: Contexto, 1993.

. Geografia socioambiental. Terra Livre, São Paulo, n.16, p. 113-132, $1^{\circ}$ Semestre/2001.

. Riscos, vulnerabilidade e abordagem socioambiental urbana: Uma reflexão a partir da RMC e de Curitiba.

Desenvolvimento e Meio Ambiente, n. 10, p. 139-148, jul./dez. 2004a. Editora UFPR.

. S.A.U. - Sistema socioambiental urbano: Uma abordagem dos problemas socioambientais da cidade. In:

MENDONÇA, F. (Org.). Impactos socioambientais urbanos. Curitiba: Editora da UFPR, pg. 185-208, 2004. 
MONTEIRO, Carlos A. Figueiredo. Geosistemas: A história de uma procura. São Paulo: Contexto, 2000.

. Teoria e clima urbano. São Paulo: IGEO/USP, 1976.

ORTEGA Y GASSET, José. A rebelião das massas. São Paulo: Martins Fontes, 2002.

PNUD - PROGRAMA DE LAS NACIONES UNIDAS PARA EL DESARROLLO. UNOPS - OFICINA DE SERVICIOS PARA PROYETOS DE LAS NACIONES UNIDAS. PROYECTO REGIONAL DE CAPACITACION EN GESTION AMBIENTAL URBANA. Guia metodologica de capacitación en gestión ambiental urbana para universidades de América Latina y el Caribe. Nova York: UNDP/UNOPS, 1997.

SANTOS, Milton. 1992: A redescoberta da natureza. São Paulo: FFLCH/USP, 1992. Aula inaugural da Faculdade de Filosofia, Letras e Ciências Humanas da Universidade de São Paulo, em 10 de março de 1992.

. Da totalidade ao lugar. São Paulo: Edusp, 2005.

SOUZA SANTOS, Boaventura de Souza. (Org). A globalização e as ciências sociais. Rio de Janeiro: Cortez, 2005.

SERRES, Michel. Le contrat naturel. Paris: Flamarion, 1993.

VEIGA, José Eli da. A emergência socioambiental. São Paulo: Editora Senc, 2007.

Recebido em abril de 2009

Aceito em agosto de 2009 